\title{
Stationary outdoor sun-protective canopies as a mean of improving of lighting environment in the premises of civil buildings in the hot and sunny climate with clear sky conditions
}

\section{Introduction}

The design of natural lightings` systems in southern regions with sunny climate needs to consider an affect of external sun-protective devices, as well as a character of external lighting. The latter in the case considered much differs from the standard overcast sky conditions of Commission Internationale de l'éclairage (C.I.E.). In sunny climate the character of outdoor lighting is determined as lighting in «clear sky» conditions. ${ }^{1-4}$ The values of «q» factor, which determine the uniform luminance of sky vault with diffused and sun lighting in graphical form are shown on Figures 1-3. The curves shown have different character, depending on sky vault conditions, aspect of window openings and presence or absence of sun-protective devices. Date of «q» factor values are quoted in Table $1 .^{5-8}$

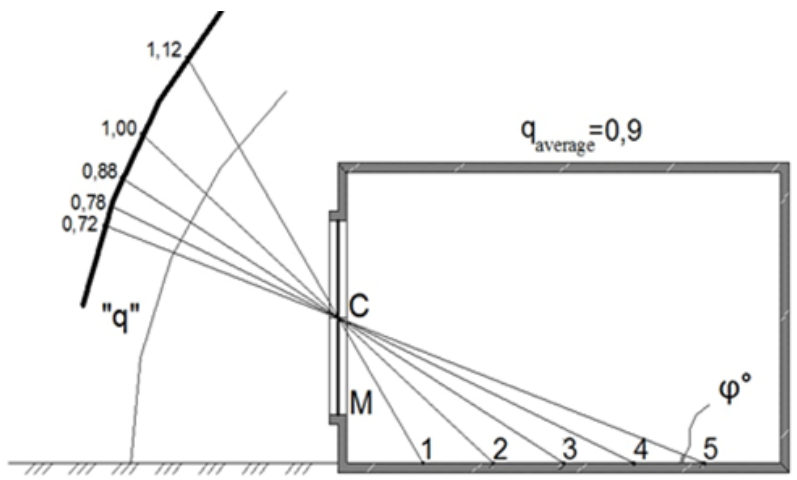

A-without external sun-protection devices.

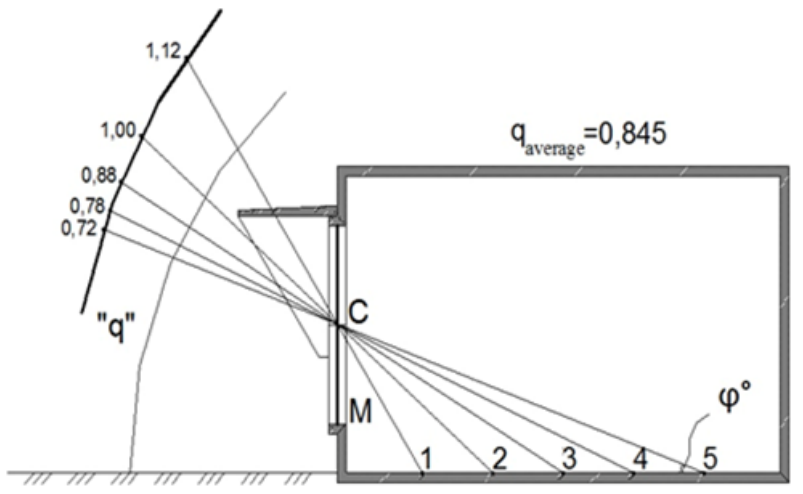

B-with external sun-protection devices

Figure I Non-uniform luminance of sky-vault under diffused external lighting a premise considered, observed from design points.

«C»-The middle point of a window opening.

«M»- Design point of insolation.

I, 2, 3,4, 5 - Design points for daylight factor' calculations.
Volume 3 Issue 2 - 2017

\section{Sergey V Stetsky}

Department of Buildings and structures design, Moscow State

University of Civil Engineering, Russia

Correspondence: Sergey V Stetsky, Buildings and structures design, Moscow State University of Civil Engineering, Russia, Email StetskiySV@mgsu.ru

Received: May 02, 2017 | Published: July 24, 2017

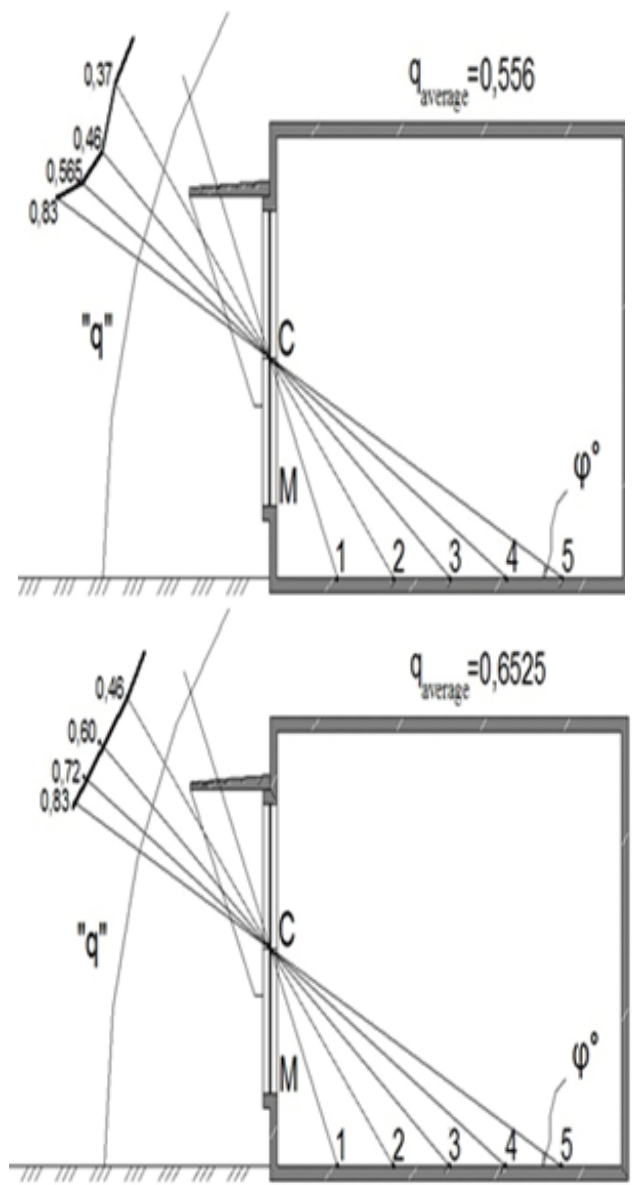

A - South-eastern aspect.

B -Southern aspect. 


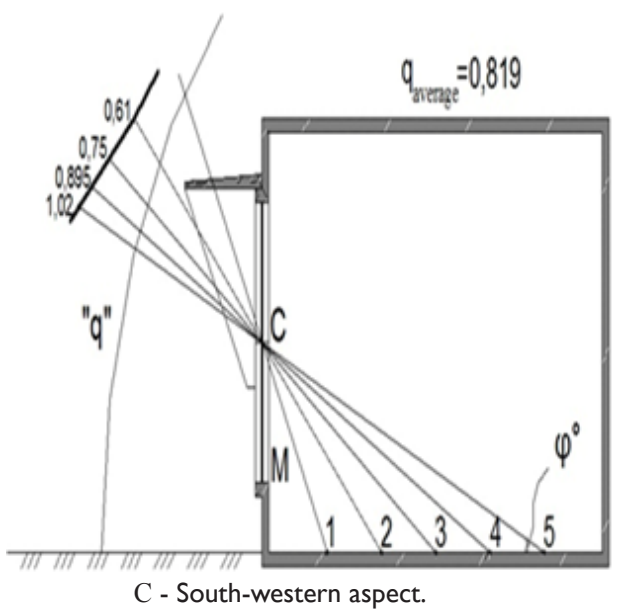

Figure 2 Non-uniform luminance of a sky-vault under sunny external lighting for a premise considered without external sun-protection devices, observed from design points.

«C»"-The middle point of a window opening.

«M»'- Design point of insolation.

I, 2, 3, 4, 5 - Design points for daylight factor' calculations.
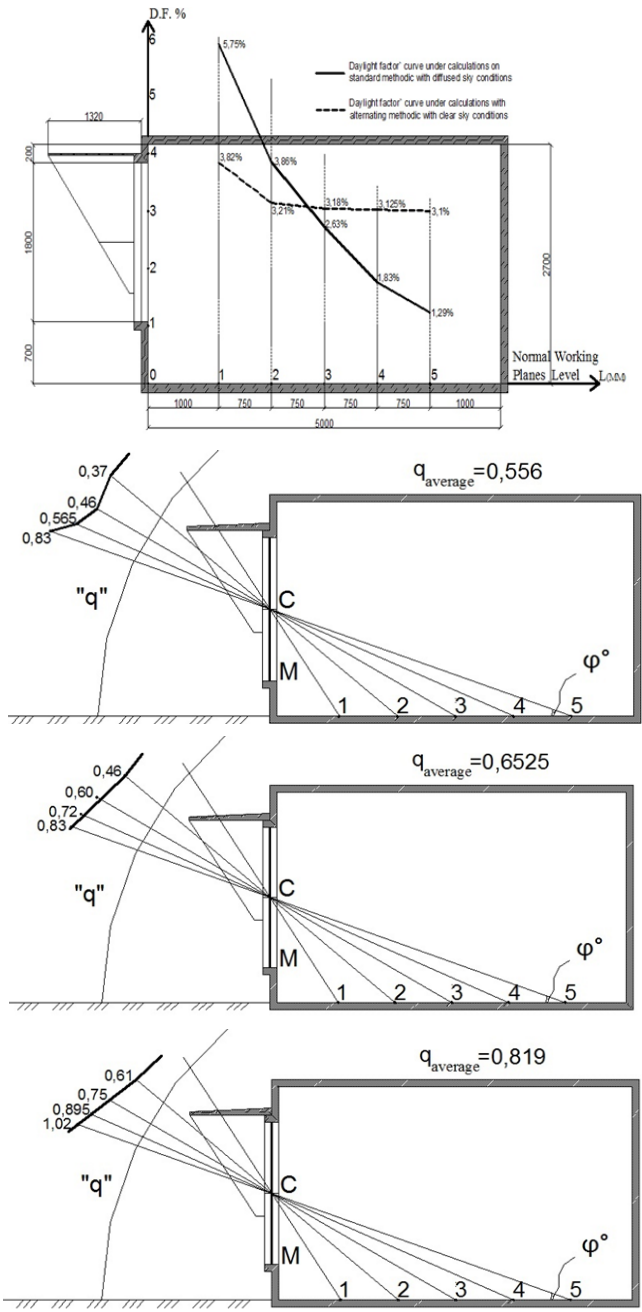

Figure 3 Non-uniform luminance of a sky-vault under sunny external lighting for premise considered with external sun-protection devices, observed from design points. 
Table I The values of «q» factor, showing the non-uniform sky' luminance under different sky-vault conditions for a premise concerned

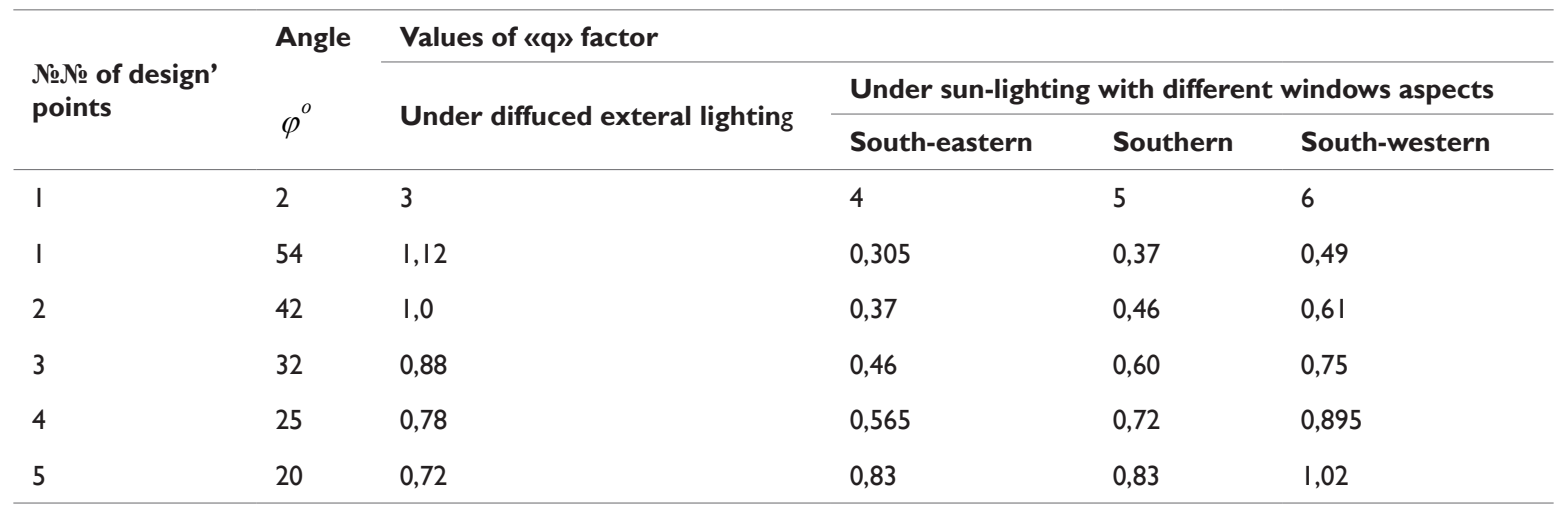

The theoretical and field investigations were conducted, based on examination of real residential premise in Beirut, Lebanon, which was chosen as an experimental site. In the room considered, which originally had no sun-protection, a temporary model of sun-protective canopies over a and below window were constructed. The canopies were painted in a light-grey colour. These permits to conduct lighting researches with sun-protective devices, as well as without these units see Figures $4 \& 5$. As a result of scientific investigations, the positive role of sun protection in form of canopies (awnings) on the natural lighting of interiors levels in the premises of civil buildings in the sunny climatic conditions with respect of external lighting on «clear sky» basis.

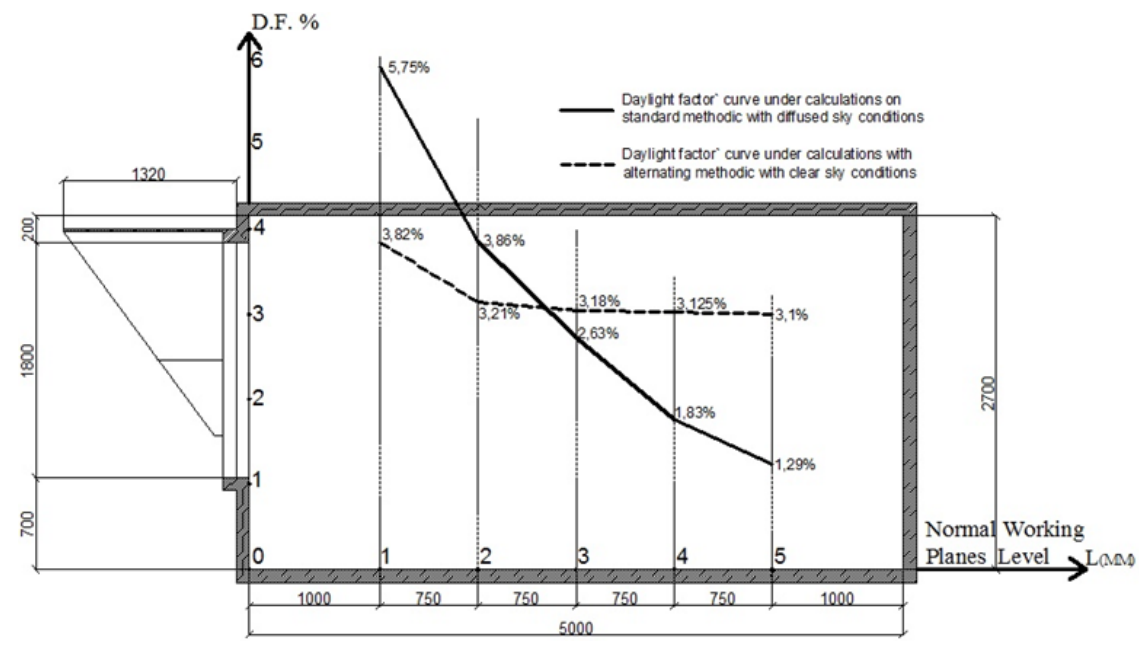

Figure 4 Theoretical daylight factor' graphs for a premise considered, determined on different design methodics with use of external sun-protection devises.

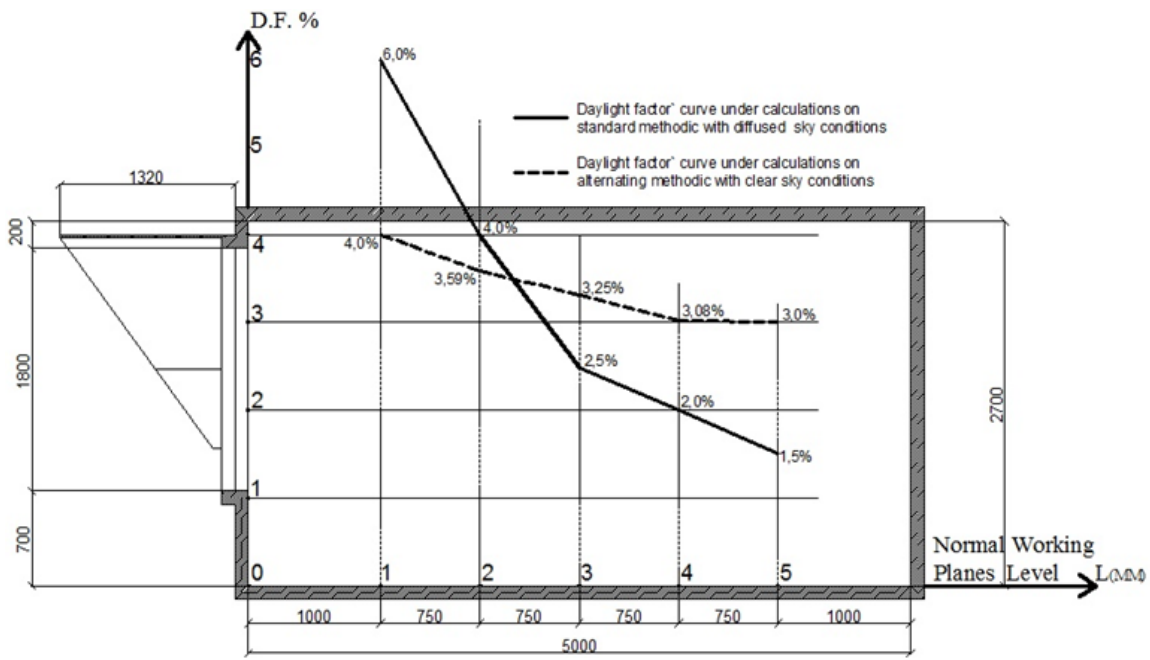

Figure 5 Field-determined daylight factor` graphs for a premise considered, investigated under conditions of diffused or clear sky with external sun-protection devices. 


\section{Conclusion}

i. The values of a «daylight factor», determined experimentally and theoretically on the basis of standard "overcast sky» method of calculation and on the basis of alternating «clear sky» method of calculation, differ a lot: Without canopies above windows this is explained mainly by the difference in values of «q» factor, which determines a non-uniform luminance of a sky vault: for standard diffuseced and alternating solar outdoor lighting.

ii. Calculated and experimentally determined daylight factor values under "clear sky» conditions are not only more even along the depth of a premise, but also are much greater in the far most from a window design point of an interior, as compared with the same values of a daylight factor, found with the standard «overcast sky» lighting conditions. This proves the matching of a daylight factor considered the requirements of the Building Codes on natural lighting of interiors to the best advantage.

iii. A significant lighting efficiency of external stationary canopies was shown in the case of taking into consideration reflected light flows from lower canopies in daylight factor' calculations on the base of "clear sky» method. Such an influence of sunprotection is similar on its influence the effect of reflected solar flows from the adjacent to a building ground surfaces.

iv. In the case of diffused external natural lighting, canopies over a window reduce external lighting, due to sky vauld blending, much more, than lower canopies increase it due to reflecting effect.

v. Contrary, in the case of solar lighting, canopies over windows reduce internal lighting in less degree, than lower canopies increase it, reflecting solar flows under the «clear sky» lighting conditions.

\section{Acknowledgments}

None.

\section{Conflicts of interest}

The author declares that there are no conflicts of interest.

\section{Funding}

None.

\section{References}

1. Gusev NM. Fundamentals of building physics. Moscow; 1975;438.

2. Soloviev AK. Environmental physics. ASV editorial. 2008;341.

3. Stetsky SV. Stationary sun-screening means as a factor of architectural expression of buildings and ensuring comfortable international microclimatic regimes in their premises for hot sunny climate. Nauchnoeobozrenie. 2014;8:572-579.

4. Stetsky SV. Aestetics of civil buildings when using stationary sunscreeningmeans in them under conditions of hot climate. PGS. 2015;7:76-80

5. Stetsky SV, Khodeyr V. Indor lighting environment in residential buildings with use of combined sun-protection devices. Vestnik MGSU. 2012;839-45.

6. Stetsky SV, Khodeyr VA. Efficient sun-protection devices in civil buildings' construction in regions with hot sunny climate. Vestnik MGSU. 2012;7:9-15.

7. Loviev AK. Assessment of lighting environment of industrial premises under clear sky conditions. Svetotechnika. 1987;7:12-14.

8. Soloviev AK. Accounting the influence of reflected light in design of internal lighting in industrial buildings with systems of roof lights under non-uniform light' distribution. A digest of scientific works of architectural chair of Moscow civil engineering institute. Moscow; 1974;73-82. 